\title{
Comparison of rating-based and choice- based conjoint analysis models. A case study based on preferences for iced coffee in Norway
}

Article

Accepted Version

Creative Commons: Attribution-Noncommercial-No Derivative Works 4.0

Asioli, D., Næs, T., Øvrum, A. and Almli, V. L. (2016)

Comparison of rating-based and choice-based conjoint analysis models. A case study based on preferences for iced coffee in Norway. Food Quality and Preference, 48 (Part A). 174 - 184. ISSN 0950-3293 doi:

https://doi.org/10.1016/j.foodqual.2015.09.007 Available at https://centaur.reading.ac.uk/76529/

It is advisable to refer to the publisher's version if you intend to cite from the work. See Guidance on citing.

To link to this article DOI: http://dx.doi.org/10.1016/j.foodqual.2015.09.007

Publisher: Elsevier

All outputs in CentAUR are protected by Intellectual Property Rights law, including copyright law. Copyright and IPR is retained by the creators or other copyright holders. Terms and conditions for use of this material are defined in the End User Agreement. 


\section{www.reading.ac.uk/centaur}

\section{CentAUR}

Central Archive at the University of Reading

Reading's research outputs online 


\title{
Comparison of Rating-Based and Choice-Based Conjoint Analysis Models.
}

\section{A case study based on Preferences for Iced Coffee in Norway}

\author{
Asioli, D. ${ }^{11,4}$, Næs, T. ${ }^{1,2}, \emptyset_{\text {vrum A. }}{ }^{3}$, Almli, V.L. ${ }^{1}$
}

${ }^{1}$ Consumer and Sensory Science - Division Food Science

Nofima AS, PO Box 210, 1431 Ås, Norway.

${ }^{2}$ University of Copenhagen, Faculty of Life Sciences,

Department Food Science, Rolighedsvej 30, 1958 Fredriksberg Copenhagen, Denmark.

${ }^{3}$ Urbanet Research

P.O. Box 337, NO-0101 Oslo, Norway.

${ }^{4}$ School of Economics and Business, Norwegian University of Life Sciences,

Universitetstunet 3, Ås, Norway.

${ }^{1}$ Corresponding author. 


\begin{abstract}
The authors compare two conjoint analysis approaches eliciting consumer preferences among different product profiles of iced coffees in Norway: Rating-based and Choice-based conjoint experiments. In the conjoint experiments, stimuli were presented in the form of mock-up pictures of iced coffees varying in coffee type, production origin, calorie content and price, following an orthogonal design. One group of participants $(n=101)$ performed a rating task of 12 iced coffees whereas another group $(n=102)$ performed a choice task on 20 iced coffees presented in eight triads. Then, all participants performed self-explicated rating and ranking evaluations of the iced coffee attributes. The rating data were analysed by a Mixed Model ANOVA while the choice data were analysed by a Mixed Logit Model. Both models include conjoint factors, demographic variables and their interactions. Results show that the two approaches share similar main results, where consumers prefer low calorie and low price iced coffee products. However, additional effects are detected within each of the two approaches. Further, self-explicated measures indicate that coffee type is the primary attribute for consumers' selection of iced coffee. The two conjoint approaches are compared and discussed in terms of experimental designs, data analysis methodologies, outcomes, user-friendliness of the results interpretation, estimation power and practical issues.
\end{abstract}

Key words: Conjoint, Rating task, Choice task, Method comparison, Consumer, Iced coffee, Norway. 


\section{INTRODUCTION}

\subsection{Experimental consumer studies: Multi-Attribute Valuation (MAV)}

Measuring consumers' preferences for goods and services has in recent decades been a significant challenge both in science and for practitioners, for example for product development and marketing purposes (Lusk \& Shogren, 2007; Louviere et al., 2000). Among the different preference study techniques, Stated Preference (SP) methods are the most frequently applied (Bateman et al., 2002). SP methods are very useful and versatile and are used for a number of different purposes, including quantifying the individuals' economic valuation or Willingness To Pay (WTP) for a certain good or service (Alfnes, Guttormsen, Steine, \& Kolstad, 2006; Alfnes, 2004; Bateman et al., 2002; Caputo, Nayga, \& Scarpa, 2013; Van Wezemael, Caputo, Nayga, Chryssochoidis, \& Verbeke, 2014). SP methods have the advantage that they can also provide information about hypothetical and simulated products in addition to existing products in the market. Since the mid-1990's, SP methods have dramatically increased in popularity with applications in agricultural and food economics, environmental and resources economics and health economics (Balcombe, Fraser, \& Falco, 2010; Louviere et al., 2010; Meenakshi et al., 2012; Olesen, Alfnes, Røra, \& Kolstad, 2010; Van Loo, Caputo, Nayga, Meullenet, \& Ricke, 2011).

Among SP methods the most widespread are the Multi-Attribute Valuation (MAV) techniques, dealing with products featuring multiple attributes alternatives (Louviere et al., 2000). In MAV techniques each good or service is described in terms of their attributes and the levels that these can take (Louviere et al., 2000). Then, consumers are presented with various alternative descriptions of a product or service, differentiated by varying attribute levels, and are asked to either rank, rate or choose among the various alternatives (Louviere et al., 2000; Molteni \& Troilo, 2007). 


\subsection{Conjoint analysis}

One of the most frequently used methodologies for MAV studies is conjoint analysis (CA), which has its origin in marketing (Green \& Srinivasan, 1990) and is widely applied in both academic and industry research (Annunziata \& Vecchio, 2013; De Pelsmaeker, Dewettinck, \& Gellynck, 2013; Saito \& Saito, 2013). CA is a method able to estimate the structure of consumer evaluations on a set of product profiles consisting of predetermined combinations of levels of product attributes (Green $\&$ Srinivasan, 1990). Thus the method is able to measure buyers' trade-offs among multi-attribute goods or services (Claret et al., 2012; Cox, Evans, \& Lease, 2007; Næs, Brockhoff, \& Tomic, 2010).

Broadly speaking there are two main CA categories: (i) acceptance-based approaches, which require the individual to rate each alternative product according to their degree of hypothetical purchase intention (here called RBCA) and (ii) preference-based approaches, where consumers are required to express their preferences either in terms of ranks or of choices among several alternative products with varying levels of attributes (here called CBCA).

Several variants of rating scales for acceptance methods have been developed and are commonly used in consumer testing (Hein, Jaeger, Carr, \& Delahunty, 2008). We will here focus on Willingness To Buy (WTB) evaluated on a 9-point category scale ranging from 1 (Extremely unlikely) to 9 (Extremely likely). Choice Experiments (CEs) originate in economics and are increasingly expanding to different fields such as transportation, environment, health, food and marketing (Gracia \& de Magistris, 2013; Haaijer, Kamakura, \& Wedel, 2001; Lusk \& Schroeder, 2004; Van Loo et al., 2011; Yangui, Akaichi, Costa-Font, \& Gil, 2014). The underlying hypothesis of CEs is that obtaining preferences by having respondents choose a single preferred stimulus among a set of stimuli is a more realistic and therefore a better method for approaching actual decisions (Louviere et al., 2000). 
The literature states that there is no clear empirical evidence for choosing RBCA models over CBCA models, and vice versa (Moore, 2004) in terms of experimental designs techniques, data analysis methodologies, outcomes, user-friendliness, estimation power and practical issues. It is therefore important to conduct more research comparing the two models in different settings, possibly by systematically varying design parameters (Karniouchina, Moore, van der Rhee, \& Verma, 2009; Moore, 2004).

\subsection{Rating versus choice experiments modelling}

Rating and choice-based CA experiments employ different experimental designs and modelling approaches to estimate models that predict consumer preferences (Louviere \& Woodworth, 1983). The literature shows that preferences vary across contexts and elicitation processes (Payne, Bettman, \& Johnson, 1992), suggesting that there may be systematic differences between RBCA and CBCA elicitation models (Moore, 2004). First of all, an hypothesis put forward is that CBCA tasks are more similar to real market place behavior than profile ratings, which may lead to a greater external validity of CBCA (Elrod, Louviere, \& Davey, 1992). Secondly, in terms of information produced, CBCA may produce less information than individual rating tasks (Lusk, Fields, \& Prevatt, 2008; Moore, 2004). Thirdly, choice tasks are expected to be easier to perform than rating tasks since respondents can make choices independently without worrying about rating scale consistency over profiles (Moore, Gray-Lee, \& Louviere, 1998) and with less mental processing (Næs, Brockhoff, et al., 2010). Fourthly, since only one choice is made in CBCA a larger number of profiles can sometimes be presented to consumers. An important exception to this is when real food products have to be tasted by the consumer. In this case, a RBCA approach may be preferred in order to limit sensory fatigue with the number of products. Fifth, CBCA experimental designs as well as data analysis are more complex (Street \& Burgess, 2007; Train, 2009) than RBCA (Næs, Brockhoff, et al., 2010) which is based on standard well established ANOVA (ANalysis Of VAriance). Finally, RBCA models present results directly in the same units as the rating scores 
while for the CBCA the size of the coefficients can only be considered relative to each other. A common approach is then to convert CBCA coefficients into willingness-to-pay values expressed in monetary units, allowing an easy interpretation of results. However this is only possible if one of the conjoint factors in the experimental design is price (Hole, 2007).

\subsection{Self-explicated tests}

Another important way of collecting MAV data is to use self-explicated tests. Contrary to conjoint analysis, these tests consist in simply asking the consumer what product attributes are the most important for product selection (Sattler \& Hensel-Börner, 2003). The approach is straightforward and does not require any complex design or data analysis. In the present case study, the selfexplicated tests will be limited to investigating the importance of four iced coffee attributes, without investigating consumer preferences for actual sublevels of the attributes.

\subsection{Application based on iced coffee}

Iced coffee was introduced on the Norwegian food market in 1999 by one of the main Norwegian dairy companies. Since then, other brands have followed up with a subsequent growth of consumption in the recent years (Asioli, Næs, Granli, \& Lengard Almli, 2014). As the product range of iced coffee on the Norwegian market is expanding, more information is needed for food companies for a better understanding of consumer preferences and choice attributes for this product category. Therefore, it is relevant to consider the impact of various extrinsic factors that influence consumer food choice. Getting more information from consumers is particularly useful for iced coffee producers in Scandinavia, considering that Scandinavian countries have some of the world's highest levels of coffee consumption, with $7.2 \mathrm{~kg}$ per capita in Norway (CaffeineInformer, 2015).

To the best knowledge of the authors, there are only two studies which investigated factors that influence consumer preferences of iced coffee. Petit \& Sieffermann (2007) investigated the effect of 
the physical testing environment on liking and consumption of iced coffee by French consumers while Asioli et al., (2014) investigated extrinsic product factors and individual characteristics affecting consumers' Willingness To Buy (WTB) iced coffee from rating evaluations in Norway. The present paper is partially based on the same consumer study as the latter reference, but focuses on method comparisons and utilizes an additional part of the original data material, namely choicebased willingness to buy.

\subsection{Objective}

The primary objective of this study is to compare RBCA and CBCA models of iced coffees varying in extrinsic parameters. The models will study conjoint effects and their interaction with consumer demographic characteristics. Practical issues, user-friendliness, interpretation and concrete results of the two approaches will be discussed. In addition, a self-explicated test of attributes' importance will be reported for the purpose of investigating its potential role in this type of studies as complementary to conjoint analysis.

\section{MATERIALS AND METHODS}

\subsection{Consumer test}

A sample of 203 consumers was recruited in the region south of Oslo, Norway in November 2012; see Asioli et al. (2014) for details. The test included four sessions and was conducted for two separate groups of consumers confronted with different conjoint tasks: a rating group $(n=101)$ and a choice group $(n=102)$. Assignment to one group or the other was performed randomly by the computer system. Selected consumer characteristics for the two groups are presented in Table 1.

Table 1 - Selected socio-demographic characteristics of the consumer groups 
As can be seen, the two consumer groups present quite similar socio-demographic characteristics. In terms of gender, one can see that both groups are slightly biased towards women, especially the rating group. The two groups are comparable in terms of mean age, BMI and occupation since there are not statistically significant differences at a $5 \%$ level for any of them with p-values $=0.7,0.8$ and 0.3 , respectively. Regarding the place of residence, consumers in the rating group tend to live more frequently in towns and less frequently on the countryside than consumers in the choice group. The groups have similar shares of respondents living in a large city (Oslo).

In the introductory session, a warm-up sample of iced coffee was served to the consumers in neutral plastic cups in order to focus the consumers on the product category. All participants received the same sample so that the warm-up sample would prime all participants identically. In the first test session, the conjoint task, consumers evaluated different iced coffee profiles presented on a computer screen according to their purchase intention. This session is described in details below separately for the rating and for the choice consumer groups. The second test session involved informed liking evaluations of several iced coffee samples in an evoked context condition and is not investigated in this paper. The last session consisted of a questionnaire investigating the consumers' consumption habits for coffee and iced coffee (Asioli et al., 2014) and some socio-demographic characteristics.

The questionnaire session also included a self-explicated test based on direct rating and direct ranking of the four iced coffee attributes. The first question asked to the consumers was: "When choosing iced coffee, how important is the coffee strength/country of production / price / calories content) for you?". Each of the attributes was evaluated on a 5-point scale anchored at "Not important at all" and "Very important". The second question asked was: "When choosing iced coffee, what is most important to you? Rank the attributes from the most to the least important". The attributes were ranked by moving them in ordered boxes with the mouse on screen. The 
attribute-ranking task was not performed right after the attribute-rating task in order to minimize carry over effects. For both tasks, the attributes were displayed in randomized order across participants.

Finally, in order to estimate the user-friendliness of each conjoint task the consumers were asked, "How easy / difficult was it to complete the questions where you got to see pictures of various iced coffees with related information?" Participants responded on a 7-point scale anchored as "Very easy" to "Very complicated/demanding". The participants were seated in separate booths. Data collection was performed on individual computers in the EyeQuestion system (Logic8 BV, The Netherlands).

\subsection{Iced coffee products}

Attributes and attribute levels for the iced coffee profiles presented to the consumers were selected based on focus group results; see Asioli et al. (2014) for details. Table 2 shows the four attributes and levels that were selected: coffee type, calorie content and production origin with two levels each, and price with three levels.

\section{Table 2 - Attributes and levels used in the conjoint designs}

\subsection{Rating task}

To test the attribute effects on consumers' preference while limiting the number of product profile presentations, a fractional factorial design of 12 samples (see appendix A) was constructed based on the attributes and levels presented in Table 2. This orthogonal array design was created with the $\% M k t E x$ macro (used the standard way without specifying any special options) for Efficient Factorial Designs in the statistical software package SAS version 9.3 (Kuhfeld, 2010). 
Photographs of 12 mock-up products, one for each product profile, were created by a graphic designer (Figure 1). The pictures were presented monadically on computer screen and following a balanced randomized order across consumers (Macfie, Bratchell, Greenhoff, \& Vallis, 1989). Prior to the task, a standard profile picture was shown pointing at the four attributes of interest (only indicating the attributes without any specific level) in order to inform consumers of the location of relevant information on the pictures. For each picture, consumers' willingness to buy (WTB) was elicited with the question: "Imagine that you are purchasing iced coffee. How likely is it that you would buy this particular iced coffee?” Answers were gathered on a 9-point scale from 1 (Extremely unlikely) to 9 (Extremely likely).

\section{Figure 1 - One of the iced coffee profiles}

\subsection{Choice task}

An orthogonal choice design composed of eight choice sets of three alternatives each was generated with the \%Choiceff macro (used the standard way without specifying any special options) for Efficient Choice Designs in SAS version 9.3 (see appendix B). The design presented a relative Defficiency of 93.2, which indicates a high balance and orthogonality (Kuhfeld, 2010). It featured 20 unique samples, that is to say eight additional product profiles to the 12 used in the rating task, where all of them were taken from the full factorial design.

The eight triads of ice coffee profiles were displayed successively on screen in the form of photographs (see Figure 1). Product presentation was randomized across participants both at choice set level and at product level within choice sets. For each choice-set, consumers' probability of buying was elicited with the question: "Imagine that you are purchasing iced coffee. Which of these iced coffees are you most likely to buy?" and participants answered by clicking on one of the three alternatives. 


\subsection{Data analysis}

\section{Rating data}

In conjoint experiments based on rating scales (here the 9-point WTB scale), the population effects from consumer evaluations are typically analysed by Mixed Model ANOVA (Næs, Brockhoff, et al., 2010). In this ANOVA model, fixed and random effects are combined usually assuming normal distribution for the random part (Næs et al., 2010). We have used the model proposed by Næs et al., (2010) with simultaneous ANOVA of the conjoint variables and categorical consumer characteristics. As conjoint variables, the model includes Calories, Coffee and Origin, while Price was included as a mean centered covariate. This allowed to handle its three experimental levels in a simple manner and was considered appropriate as previous modelling on these data has indicated a linear effect of price (Asioli, Næs, Granli, \& Lengard Almli, 2014). In addition, it allows for incorporation of all two-way interactions.

As categorical consumer characteristics, Gender and Age were included, defined with two levels each. A cut at 36 years old was utilized for defining two age subgroups, which corresponds to the mean age in the choice group and gives equal sized younger/older subgroups in both rating and in choice consumer groups. The model includes the interaction between Gender and Age as well as all the interactions among conjoint variables with Gender and Age. These main effects and interactions were included as fixed factors, while a Consumer effect nested in Age and Gender was included as random factor. Furthermore, random interaction effects between Consumer and the four conjoint factors were included to account for individual preferences. The ANOVA model for consumer i, gender $\mathrm{n}$ and age group o can be written as: 
$Y_{i j k l m n o}=\mu+$ Coffee $_{j}+$ Calories $_{k}+$ Origin $_{l}+$ Price $_{m}+$ Gender $_{n}+$ Age $_{0}+$ Coffe $^{*}$ Calories $_{j k}+$ Coffee $^{*}$ Origin $_{j l}+$ Price $^{*}$ Coffee $_{j m}+$ Calories $^{*}$ Origin $_{k l}+$ Calories $^{*}$ Price $_{k m}+$ Origin $^{*}$ Price $_{l m}+$ Coffee $^{*}$ Gender $_{j n}+$ Calories $^{*}$ Gender $_{k n}+$

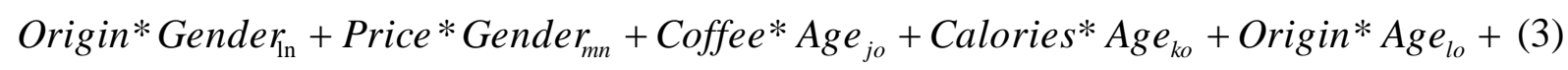
Price $^{*}$ Age $_{m o}+$ Consumer $(G e n d e r . A g e)_{i n o}+$ Coffee $*$ Consumer $(G e n d e r, A g e)_{i j n o}+$ Calories* Consumer $(\text { Gender* Age })_{i k n o}+$ Origin* Consumer $(G e n d e r, A g e)_{i \ln o}+$ Price* Consumer $(\text { Gender* Age })_{\text {imno }}+e_{i j k l m n o}$

where the $Y$ represents willingness to buy (WTB), $e$ is the random error and the indices $\mathrm{j}, \mathrm{k}, \mathrm{l}, \mathrm{m}$ correspond to the four product factors.

All calculations were made in Minitab v. 16.2.3 (Minitab Inc.).

\section{Choice data}

Choice data are routinely analysed within a random utility framework by so-called discrete choice models (DCMs) (Enneking, Neumann, \& Henneberg, 2007). The approach is based on modelling "Utility", that is to say the net benefit a consumer obtains from selecting a specific product in a choice situation. Among different DCMs, Mixed Logit (ML) models are widely applied due to their flexibility (Ortúzar, 2010; Train, 2009) and since they allow models that may better match realworld situations. This flexibility comes from the fact that one may freely include random parameters of any distribution and also correlations between random factors. By including random parameters, ML intrinsically models preference heterogeneity, i.e. inter-individual preference variations. ML models have increased in usage within sensory and consumer science in recent years in parallel with the usage of choice and ranking approaches (Almli, Øvrum, Hersleth, Almøy, \& Næs, 2015; Jaeger \& Rose, 2008; Ortúzar, 2010).

Similarly to the rating data analysis approach, two consumer characteristics were included in the ML model, namely Gender and Age. Introducing more consumer variables may disturb interpretation and make the conjoint effects weaker (Næs, Almli, Bølling Johansen, \& Hersleth, 
2010). All variables were coded using effects coding (-1; 1) (Bech \& Gyrd-Hansen, 2005), except Price which was coded in three levels respecting the original monetary units $(-6 ; 0 ; 6)$. The variables were coded as presented in Table 3.

\section{Table 3 - Variables coded and their description}

Thus, in our main specification of the model we interact conjoint variables for Coffee, Calories, Origin and Price with consumer characteristics Gender and Age.

The utility ML model for iced coffee $j$ for individual $i$ in choice occasion $t$ is written:

$$
\begin{aligned}
& U_{i j t}=\beta_{1 i} \text { Coffee }_{i j t}+\beta_{2 i} \text { Calories }_{i j t}+\beta_{3 i} \text { Origin }_{i j t}+\beta_{4 i} \text { Price }_{i j t}+B_{5 i}\left(\text { Coffee }^{*} \text { Calories }_{i j t}+\beta_{6 i}\right. \\
& (\text { Coffee } * \text { Origin })_{i j t}+\beta_{7 i}(\text { Coffee } * \text { Price })_{i j t}+\beta_{8 i}(\text { Calories } * \text { Origin })_{i j t}+\beta_{9 i}(\text { Calories } * \text { Price })_{i j t}+ \\
& \beta_{10 i}(\text { Origin } * \text { Price })_{i j t}+\beta_{11 i}(\text { Age } * \text { Coffee })_{i j t}+\beta_{12 i}(\text { Age } * \text { Price })_{i j t}+\beta_{13 i}(\text { Age } * \text { Calories })_{i j t}+\beta_{14 i} \\
& (\text { Age } * \text { Origin })_{i j t}+\beta_{15 i}(\text { Gender } * \text { Coffee })_{i j t}+\beta_{16 i}(\text { Gender } * \text { Price })_{i j t}+\beta_{17 i}(\text { Gender } * \text { Calories })_{i j t} \\
& +\beta_{18}(\text { Gender*Origin })_{i j t}+\varepsilon_{i j t}(4)
\end{aligned}
$$

The interaction effects are obtained by multiplying the columns in the data set for the corresponding main effects.

Note that the main effects of Gender, Age and their interaction are not present in Equation (4), because the utility-based ML model only distinguishes between relative effects of the conjoint factors and not the general liking level for consumers. The consumer effect is automatically incorporated here since all coefficients are considered random. Note that apart from this, the effects are the same as in the Mixed Model ANOVA model above (Equation 3).

The ML model used here assumes random parameters with normal distributions for all conjoint factors, consumer characteristics and two-way interactions. These random coefficients are further 
assumed to be independent. This model provides estimates of the mean and the standard deviation of the random conjoint parameters, their interactions and interactions among conjoint variables with Gender and Age. The ML model was estimated using the Stata module mixlogit (Hole, 2007) run in STATA 11.2 software (StataCorp LP, College Station, US). Two thousand Halton draws were used in the simulations. More details on estimation of ML models are found in Train (2009) and Hole (2007).

\section{RESULTS}

In order to detect consumer preferences for attributes Coffee type, Calories, Origin, Price and their interactions, a Mixed Model ANOVA was conducted based on 1212 observations from the rating design (101 consumers exposed to 12 product profiles). Similarly, a Mixed Logit (ML) model was conducted based on 2376 observations from the choice design (102 consumers exposed to 24 product profiles organized in eight choice sets). In the choice model, the number of observations was equal to 2376 and not 2448 , because three consumers did not declare their age.

\subsection{Rating data analysis: estimation results}

Table 4 presents the ANOVA results for the rating task for both main and interaction effects.

\section{Table 4 - Mixed model ANOVA on conjoint rating data}

\section{Main effects}

As can be seen, Calories and Price both show significant main effects. From Figure 2, one can see that consumers on average were more willing to buy cheaper products and products of lower calorie content. Their interaction effect Calories*Price is also close to significance level (p-value of 0.065). 


\section{Figure 2 - Main effects in the Mixed Model ANOVA from conjoint rating (n.s.: non- significant effects)}

\section{Interaction effects}

Three significant interactions involving consumer characteristics are revealed: Price*Age, Price*Gender, and Origin*Age (Figure 3). Older consumers show higher willingness to buy (WTB) iced coffee than younger consumers, especially at higher prices. At low prices, males and females have the same willingness to buy, but at high prices, females show higher willingness to buy than males. Finally, while for iced coffee of Italian origin younger and older consumers show a similar willingness to buy, for Norwegian origin older consumers are much more willing to buy at higher prices.

It is interesting to note that the random interactions between the conjoint factors and consumer are all strongly significant, indicating that there are strong individual differences in WTB for all attributes. Note in particular the very strong individual difference for the Coffee type attribute (Table 4).

\section{Figure 3 - Significant interaction effects from the rating approach}

\subsection{Choice data analysis: estimation results}

The parameter estimates of the ML model for the main effect of the conjoint variables and their interaction terms with socio-demographic variables are listed in Table 5. The average parameter values and their significance levels are presented to the left while the corresponding standard deviations and significance levels are presented to the right. The latter values give an indication of the individual variability around the mean parameter value. These values correspond conceptually to the information content in the interactions between the consumer effect and conjoint variables in 
the rating approach. The null hypothesis that all coefficients are zero is rejected by a Wald test (pvalue $<0.0005)$ which implies that the attributes chosen in this research are considered relevant by consumers.

Table 5 - Estimated parameters for ML model with conjoint variables' main effects and interactions, and interactions with socio-demographic variables

\section{Main effects}

In accordance to the rating task results, on average consumers in the choice group prefer low prices and low calories (Figure 4). The main effect for Coffee type is not significant, however the corresponding standard deviation coefficient is very strong (value 2.214) and highly significant. The latter reveals a strong preference heterogeneity for this attribute despite no preference on average for the group. About half the participants chose Latte in priority while the other half chose Espresso in priority, indicating a split market on this attribute. The only substantial difference from the rating data is the significance of Origin, with a preference on average for an Italian origin. Note, however, that in this model as well calorie content has a stronger negative effect than origin.

Figure 4 - Main effects in the ML Model from choice-based conjoint (n.s.: non-significant effect).

\section{Interaction effects}

Regarding the interaction effects among conjoint variables, the interaction between Coffee and Price is significant. Figure 5 shows this interaction effect, where the slope of latte is higher than espresso meaning that consumers who prefer latte are also more sensitive to price than consumers who prefer espresso. 
Finally, looking at the interactions among conjoint variables and socio-demographic characteristics, we found that the interaction between Calories and Gender is significant. Figure 5 shows this interaction effect, where the difference in choice probability for low-calorie products and highcalorie products is strong for females but very low for males, showing that females are more sensitive to calorie content than males. In addition, several interactions show a significant preference heterogeneity among participants (significant standard deviations of coefficient estimates, see Table 5).

\section{Figure 5 - Significant interaction effects from the choice-based approach}

\subsection{Self-explicated measures}

Results from the direct evaluations of iced-coffee attributes in self-explicated measures are reported in Figure 6 for the total consumer sample $(n=203)$. The plot shows very similar patterns across the two measurements, i.e. rating and ranking of attributes. Coffee type is reported as the most important attribute for iced-coffee selection followed by Price, then by Calories and Origin. Thus, the direct question on attribute importance is compatible with both the choice and rating task results, where the Coffee type attribute showed preference heterogeneity among participants.

Figure 6 - Importance of iced coffee attributes by direct rating and ranking of attributes in self-explicated tests, pulled data for all consumers. Similar letters indicate non-significant differences.

\subsection{Task complexity}

Both conjoint tasks were scored as easy to perform with mean scores of 1.8 (sdev 1.1) and 2.0 (sdev 1.3) for the rating and choice tasks, respectively. A T-test showed no significant difference in this user-friendliness evaluation of the two tasks ( $\mathrm{p}$-value=0.2). 


\section{DISCUSSION}

\subsection{Comparing rating and choice designs and practical application of the tests}

Defining comparable conjoint designs of different nature is difficult since many properties must be considered both from the mathematical and the usage sides. In this study, the designs that were generated were both orthogonal designs with four conjoint attributes of two to three levels each. Similarity was further sought in terms of burden for the respondent in answering the task, and decisions were made by the experimenters to achieve this goal. Thus the rating approach was built upon 12 iced coffee profiles (12 screens for the respondent), while the choice design was built upon eight choice sets (eight screens) of three iced-coffee alternatives each. These designs scored equally on user-friendliness as evaluated by the two groups of participants (see section 3.4 above). The literature has reported that choice tasks can be perceived as easier for consumers (Moore et al., 1998); that would, however, depend on the number of conjoint factors and levels, the number of product profiles, choice sets and choice alternatives that are selected. The discrepancy in number of profiles is a problem in terms of method comparison, as the design based on 24 profile presentations is richer in data points than the design based on 12 profiles. This may possibly explain why the CBCA model was somewhat more sensitive at detecting main effects and interactions than the RBCA model. It should also be noted that if consumers had tasted the products, the number of profiles in the CBCA approach would have needed to be reduced due to sensory fatigue.

In this study a "no-choice" option was not included although it has been stated that sometimes this option may give a better market penetration prediction (Enneking et al., 2007; Haaijer et al., 2001). Such an approach was applied by Enneking et al., (2007). In the present study, it was not the purpose to predict market penetration, which is often quoted as an important argument to include a no-choice option. Further, according to Haaijer et al. (2001) consumers may choose the no-choice option for two reasons. Firstly, consumers may not be interested in the product category under 
research and for this reason choose the no-choice option. In this study only iced coffee drinkers were recruited, which implied a general acceptance of this product category. Secondly, respondents may choose the no-choice option because no alternative in the choice set is sufficiently attractive.

\subsection{Comparing computations, interpretation and results}

Similar models were computed in the two data sets, including equivalent main effect and interaction terms. It was chosen to include demographic parameters into the models, which is common practice in Mixed Logit models (Øvrum, Alfnes, Almli, \& Rickertsen, 2012). From the researchers’ perspective, the possibility to include demographic parameters in both Mixed Model ANOVA and Mixed Logit Model could be of great importance since it is possible to collect data that can be further used to investigate individual differences. Regarding the practical aspects of the analysis, we found that the ANOVA analysis of rating data was easier to perform (using Minitab v. 16.2.3) than the Mixed Logit analysis of choice data (using the mixlogit module in STATA 11.2). Note however that this may be software specific and not due to the respective methodologies.

As described in Section 3, the choice and rating approaches led to similar results, but some differences were also quite clear. The rating approach detected two highly significant main effects $(\mathrm{p}<0.001)$, no conjoint factor interactions, and three Conjoint factor * Consumer characteristic interactions ( $\mathrm{p}<0.001$ for two of these and $\mathrm{p}<0.05$ for the third one). The choice approach detected three significant main effects ( $p<0.001$ for two of these and $p<0.01$ for the third one), one interaction between conjoint factors $(\mathrm{p}<0.05)$ and one interaction between Conjoint factor * Consumer characteristic $(\mathrm{p}<0.05)$. It seems therefore that the rating approach was more sensitive in detecting consumer characteristic interaction effects, and that $\mathrm{p}$-values tended to be lower with this approach. On the other hand, it seems that the choice approach was more sensitive to main effects and interaction effects between conjoint factors. Both approaches were able to detect preference heterogeneity on Coffee type. The result differences could be due to several differences between the 
two approaches: the different type of designs, which may call for different cognitive processing by the respondents, the different design efficiencies, the different numbers of iced coffee profiles and attributes combinations presented, the different modelling approaches, or even the different groups of respondents. In particular, we should also take into account that the choice data have a larger number of observations ( 8 choice sets $\times 3$ alternatives $\times 99$ consumers $=2376$ observations) compared to rating data ( $12 \times 101$ consumers $=1212$ observations $)$, which may affect the power of detecting effects.

Regarding result interpretation, the different effects in ANOVA could be interpreted by looking directly at the p-values, sizes and signs (+/-) of the effects by using the ANOVA table and the plots for both main effects and interactions. In Mixed Logit, p-values and signs of coefficient estimates could be interpreted directly, but plots that illustrate main effects and interaction effects were constructed separately by the authors (in Minitab v. 16.2.3). This latter aspect is software dependent.

Overall, no method is a panacea. Researchers must always evaluate and trade pros and cons of each method by taking in consideration the objectives of the research.

\subsection{Self-explicated tests and conjoint tasks}

It is interesting that consumers indicated Coffee type to be the most important attribute for iced coffee selection in self-explicated measures, while main effects in the RBCA and the CBCA models indicated this attribute as non-significant for consumers' preferences on average. This highlights that by interpreting mean population effects only in conjoint studies, one may miss potential subgroups of diverging preferences. Direct attribute evaluations in self-explicated tests are quick to integrate in a questionnaire and will indicate when there is need to investigate preference heterogeneities. When that is the case, different approaches exist to identify consumer segments that differ from the mean population effect (Almli et al., 2015; Næs, Brockhoff, et al., 2010). In the present study, results in self-explicated rating and ranking confirmed each other. These two tests 
were separated by several question items in the questionnaire, such that consumers answered these tests independently from each other. On the contrary, Almli et al. (2015) found that ranking of extrinsic cheese attributes did not corroborate with rating of the same attributes. In their study, the two self-explicated tests followed directly after each other in the questionnaire, possibly forcing different interpretations of these two redundant questions.

\section{CONCLUSION}

This study compared a rating-based conjoint analysis (RBCA) to a choice-based conjoint analysis (CBCA) in the study of extrinsic attributes' effects in consumer preferences for iced coffee. Two designs of similar user-friendliness were selected for the purpose of the comparison. Results showed that the two approaches led to similar main conclusions. The RBCA presented more strongly significant effects and was more sensitive in detecting interactions between consumer characteristics and conjoint effects. On the other hand, the $\mathrm{CBCA}$ was more sensitive to main effects and interaction effects between conjoint factors, and indicated preference heterogeneities among consumers. Further, direct attribute evaluations by self-explicated measures corroborated information issued from the conjoint approaches. Drawbacks and advantages of each approach were discussed, with a slight advantage to the conjoint rating approach which was more straightforward to model and interpret in the specific software tools we utilized.

Limitations of the study lie in the fact that one of the designs collected twice the amount of data as the other one; this was a consequence of matching the task effort for the participants across approaches by using a comparable number of questions to answer (i.e. number of screens). Further, the sample size and choice of respondents from a local area do not allow for a generalization of results with regard to general preferences for iced coffee properties. Finally, future research is needed to further investigate conjoint designs differences in performance for different criteria of comparability. 


\section{Acknowledgements}

The research was conducted in Norway in the framework of the FOODCHOICE project, a userdriven project funded by the Research Council of Norway focusing on method development within consumer research. Financial support from the Research Council of Norway for the YGGDRASIL mobility program 2012-2013: Project Number 219787/F11 is acknowledged. Thanks also to the European Commission through the Marie Curie Actions Intra European Fellowship (IEF), call FP/PEOPLE-I2012-IEF - project title "Innovative Methodologies for New Food Product Development: combining Sensory Science and Experimental Economics - NEFOMET” for the support. Kjell Merok (Nofima) is thanked for designing the iced coffee products profiles.

\section{REFERENCES}

Alfnes, F. (2004). Stated preferences for imported and hormone-treated beef: Application of a mixed logit model. European Review of Agricultural Economics, 31 (1 ), 19-37.

Alfnes, F., Guttormsen, A. G., Steine, G., \& Kolstad, K. (2006). Consumers' Willingness to Pay for the Color of Salmon: A Choice Experiment with Real Economic Incentives. American Journal of Agricultural Economics, 88 (4 ), 1050-1061.

Almli, V. L., Øvrum, A., Hersleth, M., Almøy, T., \& Næs, T. (2015). Investigating individual preferences in rating and ranking conjoint experiments. A case study on semi-hard cheese. Food Quality and Preference, 39, 28-39.

Annunziata, A., \& Vecchio, R. (2013). Consumer perception of functional foods: A conjoint analysis with probiotics. Food Quality and Preference, 28(1), 348-355. 
Asioli, D., Næs, T., Granli, B. S., \& Lengard Almli, V. (2014). Consumer preferences for iced coffee determined by conjoint analysis: an exploratory study with Norwegian consumers. International Journal of Food Science \& Technology, 49(6), 1565-1571.

Balcombe, K., Fraser, I., \& Falco, S. Di. (2010). Traffic lights and food choice: A choice experiment examining the relationship between nutritional food labels and price. Food Policy, 35(3), 211-220.

Bateman, I. J., Carson, R. T., Day, B., Hanemann, W. M., Hanleys, N., Hett, T., ... Swanson, T. (2002). Economic Valuation With Stated Preference Techniques: A Manual. Cheltenham, UK: Edward Elgar.

Bech, M., \& Gyrd-Hansen, D. (2005). Effects coding in discrete choice experiments. Health Economics, 14(10), 1079-1083.

CaffeineInformer. (2015). Accessed July 1, 2015. http://www.caffeineinformer.com/caffeine-whatthe-world-drinks.

Caputo, V., Nayga, R. M., \& Scarpa, R. (2013). Food miles or carbon emissions? Exploring labelling preference for food transport footprint with a stated choice study. Australian Journal of Agricultural and Resource Economics, 57(4), 465-482.

Claret, A., Guerrero, L., Aguirre, E., Rincón, L., Hernández, M. D., Martínez, I., ... RodríguezRodríguez, C. (2012). Consumer preferences for sea fish using conjoint analysis: Exploratory study of the importance of country of origin, obtaining method, storage conditions and purchasing price. Food Quality and Preference, 26(2), 259-266. 
Cox, D. N., Evans, G., \& Lease, H. J. (2007). The influence of information and beliefs about technology on the acceptance of novel food technologies: A conjoint study of farmed prawn concepts. Food Quality and Preference, 18(5), 813-823.

De Pelsmaeker, S., Dewettinck, K., \& Gellynck, X. (2013). The possibility of using tasting as a presentation method for sensory stimuli in conjoint analysis. Trends in Food Science \& Technology, 29(2), 108-115.

Elrod, T., Louviere, J. J., \& Davey, K. S. (1992). An Empirical Comparison of Ratings-Based and Choice-Based Conjoint Models. Journal of Marketing Research, 29, 368-377.

Enneking, U., Neumann, C., \& Henneberg, S. (2007). How important intrinsic and extrinsic product attributes affect purchase decision. Food Quality and Preference, 18(1), 133-138.

Gracia, A., \& de Magistris, T. (2013). Preferences for lamb meat: A choice experiment for Spanish consumers. Meat Science, 95(2), 396-402.

Green, P. ., \& Srinivasan, V. (1990). Conjoint Analysis in Marketing: New Developments with Implications for Research and Practice. Journal of Marketing, 54(4), 3-19.

Haaijer, R., Kamakura, W. A., \& Wedel, M. (2001). The "No-Choice" Alternative in Conjoint Choice Experiments. International Journal of Market Research, 43(1), 93-106.

Hein, K. A., Jaeger, S. R., Tom Carr, B., \& Delahunty, C. M. (2008). Comparison of five common acceptance and preference methods. Food Quality and Preference, 19(7), 651-661.

Hole, A. R. (2007). Fitting mixed logit models by using maximum simulated likelihood. The Stata Journal, 7(3), 188-401. 
Jaeger, S. R., \& Rose, J. M. (2008). Stated choice experimentation, contextual influences and food choice: A case study. Food Quality and Preference, 19(6), 539-564.

Karniouchina, E. V., Moore, W. L., van der Rhee, B., \& Verma, R. (2009). Issues in the use of ratings-based versus choice-based conjoint analysis in operations management research. European Journal of Operational Research, 197(1), 340-348.

Kuhfeld, W. (2010). Marketing research methods in SAS. Cary: SAS Institute Inc.

Louviere, J. J., Flynn, T. N., \& Carson, R. T. (2010). Discrete Choice Experiments Are Not Conjoint Analysis. Journal of Choice Modelling, 3(3), 57-72.

Louviere, J.J., Hensher, D.A., Swait, J.F. \& Adamowicz, W. (2000). Stated Choice Methods: Analysis and Applications. Cambridge University Press, Cambridge.

Louviere, J. J., \& Woodworth, G. (1983). Design and analysis of simulated consumer choice or allocation experiments: an approach based on aggregate data. Journal of Marketing Research, $20,350-367$.

Lusk, J. L., Fields, D., \& Prevatt, W. (2008). An Incentive Compatible Conjoint Ranking Mechanism. American Journal of Agricultural Economics, 90 (2 ), 487-498.

Lusk, J. L., \& Schroeder, T. C. (2004). Are Choice Experiments Incentive Compatible? A Test with Quality Differentiated Beef Steaks. American Journal of Agricultural Economics , 86 (2), 467-482.

Lusk, J. L., \& Shogren, J. F. (2007). Experimental auctions. Methods and applications in economic and marketing research.Cambridge University Press, Cambridge. 
Macfie, H., Bratchell, N., Greenhoff, K., \& Vallis, L. V. (1989). Designs to balance the effect of order of presentation and first-order carry-over effects in hall tests. Journal of Sensory Studies, 4(2), 129-148.

Meenakshi, J. V, Banerji, A., Manyong, V., Tomlins, K., Mittal, N., \& Hamukwala, P. (2012). Using a discrete choice experiment to elicit the demand for a nutritious food: Willingness-topay for orange maize in rural Zambia. Journal of Health Economics, 31(1), 62-71.

Molteni, L., \& Troilo, G. (2007). Ricerche di Marketing. McGraw-Hill, Milano.

Moore, W., Gray-Lee, J., \& Louviere, J. (1998). A Cross-Validity Comparison of Conjoint Analysis and Choice Models at Different Levels of Aggregation. Marketing Letters, 9(2), 195-207.

Moore, W. L. (2004). A cross-validity comparison of rating-based and choice-based conjoint analysis models. International Journal of Research in Marketing, 21(3), 299-312.

Næs, T., Almli, V. L., Bølling Johansen, S., \& Hersleth, M. (2010). Alternative methods for combining design variables and consumer preference with information about attitudes and demographics in conjoint analysis. Food Quality and Preference, 21(4), 368-378.

Næs, T., Brockhoff, P., \& Tomic, O. (2010). Statistics for sensory and consumer science. Wiley, Chichester, UK.

Olesen, I., Alfnes, F., Røra, M. B., \& Kolstad, K. (2010). Eliciting consumers’ willingness to pay for organic and welfare-labelled salmon in a non-hypothetical choice experiment. Livestock Science, 127(2-3), 218-226.

Ortúzar, J. de D. (2010). Estimating individual preferences with flexible discrete-choice-models. Food Quality and Preference, 21(3), 262-269. 
Øvrum, A., Alfnes, F., Almli, V. L., \& Rickertsen, K. (2012). Health information and diet choices: Results from a cheese experiment. Food Policy, 37(5), 520-529.

Payne, J. W., Bettman, J. R., \& Johnson, E. J. (1992). Behavioral Decision Research: A Constructive Processing Perspective. Annual Review of Psychology, 43(1), 87-131.

Petit, C., \& Sieffermann, J. M. (2007). Testing consumer preferences for iced-coffee: Does the drinking environment have any influence? Food Quality and Preference, 18(1), 161-172.

Saito, H., \& Saito, Y. (2013). Motivations for Local Food Demand by Japanese Consumers: A Conjoint Analysis with Reference-Point Effects. Agribusiness, 29(2), 147-161.

Sattler, H., \& Hensel-Börner, S. (2003). A comparison of conjoint measurement with selfexplicated approaches. In A. Gustafsson, A. Herrmann, \& F. Huber (Eds.), Conjoint Measurement: Methods and Applications (pp. 147-159). Berlin: Springer.

Street, D. J., \& Burgess, L. (2007). The construction of optimal stated choice experiment. Theory and methods. Wiley, US.

Train, K. (2009). Discrete choice methods with simulation. Cambridge University Press, UK.

Van Loo, E. J., Caputo, V., Nayga, R. M., Meullenet, J.-F., \& Ricke, S. C. (2011). Consumers’ willingness to pay for organic chicken breast: Evidence from choice experiment. Food Quality and Preference, 22(7), 603-613.

Van Wezemael, L., Caputo, V., Nayga, R. M., Chryssochoidis, G., \& Verbeke, W. (2014). European consumer preferences for beef with nutrition and health claims: A multi-country investigation using discrete choice experiments. Food Policy, 44, 167-176. 
Yangui, A., Akaichi, F., Costa-Font, M., \& Gil, J. M. (2014). Are ranking preferences information methods comparable with the choice experiment information in predicting actual behaviour? In EAAE 2014 Congress “Agri-Food and Rural Innovations for Healthier Societies” (p. 13). Ljubljana, Slovenia. 
Appendix A - Rating design 
Appendix B - Choice design 
Table 1 - Selected socio-demographic characteristics of the consumer groups

\begin{tabular}{lcc}
\hline CHARACTERISTICS & $\begin{array}{c}\text { RATING GROUP } \\
(\boldsymbol{n}=\mathbf{1 0 1})\end{array}$ & $\begin{array}{c}\text { CHOICE GROUP } \\
(\boldsymbol{n}=\mathbf{1 0 2})\end{array}$ \\
\hline Gender & $34(33.7 \%)$ & $40(39.2 \%)$ \\
Men & $67(66.3 \%)$ & $59(57.8 \%)$ \\
Women & & $3(3.0 \%)$ \\
n/a & & \\
Age (years) & $19-57$ & $21-56$ \\
Min-max & $34.6(10.7)$ & $36.0(10.6)$ \\
Mean (SDev) & & $24.6(4.6)$ \\
BMI & $24.1(3.2)$ & $13(12.7 \%)$ \\
Mean (SDev) & & $64(62.7 \%)$ \\
Residence & $12(11.9 \%)$ & $22(21.6 \%)$ \\
City & $73(72.3 \%)$ & $3(2.9 \%)$ \\
Town & $16(15.8 \%)$ & $3(2.9 \%)$ \\
Countryside & & $37(36.3 \%)$ \\
n/a & & $62(60.8 \%)$ \\
Occupation & $39(38.6 \%)$ & 0 \\
Student & $61(60.4 \%)$ & 0 \\
Employed (full time, part time) & $1(1.0 \%)$ & \\
Unemployed & 0 & 0 \\
Retired & & \\
n/a & 0 & \\
\hline Source: & & \\
\hline
\end{tabular}

Source: our elaboration. 
Table 2 - Attributes and levels used in the conjoint designs

\begin{tabular}{lll}
\hline ATTRIBUTES & LEVELS \\
\hline Coffee type & 1 & Latte \\
& 2 & Espresso \\
Calories & 1 & $60 \mathrm{kcal} / 100 \mathrm{ml}$ \\
& 2 & $90 \mathrm{kcal} / 100 \mathrm{ml}$ \\
Origin & 1 & Norway \\
& 2 & Italy \\
Price & 1 & $17 \mathrm{NOK}(\approx € 2.0)$ \\
& 2 & $23 \mathrm{NOK}(\approx € 2.7)$ \\
& 3 & $29 \mathrm{NOK}(\approx € 3.4)$
\end{tabular}


Table 3 - Variables coded and their description

\begin{tabular}{|c|c|}
\hline VARIABLE & DESCRIPTION \\
\hline Coffee & If Espresso: 1 ; otherwise (Latte): -1 \\
\hline Calories & If $90 \mathrm{kcal} / 100 \mathrm{ml}: 1 ;$ otherwise (60 kcal/100ml): -1 \\
\hline Origin & If Italy: $1 ;$ otherwise (Norway): -1 \\
\hline Price & If 17 NOK: $-6 ;$ if 23 NOK: $0 ;$ if 29 NOK: 6 \\
\hline Gender & If Male: $1 ;$ otherwise (Female): -1 \\
\hline Age & If age is $37-56: 1 ;$ otherwise $21-36$ (younger): -1 \\
\hline
\end{tabular}


Table 4 - Mixed model ANOVA on conjoint rating data

\begin{tabular}{|c|c|c|c|c|}
\hline SOURCES OF VARIATION & D.F. & MS & F-VALUE & P-VALUE \\
\hline Coffee & 1 & 1.61 & 0.12 & 0.733 \\
\hline Calories & 1 & 64.48 & 29.00 & $0.000^{* * * *}$ \\
\hline Origin & 1 & 6.19 & 1.99 & 0.161 \\
\hline Price & 1 & 362.83 & 392.33 & $0.000^{* * * *}$ \\
\hline Gender & 1 & 30.21 & 1.86 & 0.176 \\
\hline Age & 1 & 33.95 & 2.09 & 0.151 \\
\hline Coffee*Calories & 1 & 1.35 & 1.46 & 0.228 \\
\hline Coffee* Origin & 1 & 1.11 & 1.20 & 0.274 \\
\hline Price*Coffee & 1 & 0.33 & 0.36 & 0.548 \\
\hline Calories*Origin & 1 & 1.35 & 1.46 & 0.228 \\
\hline Price*Calories & 1 & 3.16 & 3.42 & 0.065 \\
\hline Price*Origin & 1 & 0.00 & 0.00 & 0.963 \\
\hline Coffee*Gender & 1 & 10.23 & 0.53 & 0.469 \\
\hline Calories*Gender & 1 & 5.02 & 2.05 & 0.156 \\
\hline Origin*Gender & 1 & 1.49 & 0.37 & 0.547 \\
\hline Price*Gender & 1 & 12.69 & 13.72 & $0.000^{* * *}$ \\
\hline Coffee*Age & 1 & 32.72 & 1.69 & 0.197 \\
\hline Calories*Age & 1 & 1.47 & 0.60 & 0.441 \\
\hline Origin*Age & 1 & 16.53 & 4.05 & $0.047^{*}$ \\
\hline Price*Age & 1 & 13.78 & 14.90 & $0.000^{* * * *}$ \\
\hline Gender*Age & 1 & 1.73 & 0.11 & 0.745 \\
\hline Consumer(Gender; Age) & 97 & 16.24 & 0.68 & 0.980 \\
\hline Consumer*Coffee(Gender; Age) & 97 & 19.36 & 20.93 & $0.000^{* * * *}$ \\
\hline Consumer*Calories(Gender; Age) & 97 & 2.45 & 2.65 & $0.000^{* * * *}$ \\
\hline Consumer*Origin(Gender; Age) & 97 & 4.08 & 4.42 & $0.000^{* * *}$ \\
\hline Price*Consumer(Gender; Age) & 97 & 4.59 & 4.96 & $0.000^{* * * *}$ \\
\hline Error & 705 & 0.93 & & \\
\hline Total & 1211 & & & \\
\hline
\end{tabular}


R-Square $=88.94 \%$. This must be interpreted with care in models with consumer effects (see Næs, Brockhoff, et al., 2010).

${ }^{* * *}$ and ${ }^{* * *}$ indicate significant effects at $0.05,0.01$ and 0.001 levels, respectively. 
Table 5 - Estimated parameters for ML model with conjoint variables' main effects and interactions, and interactions with socio-demographic variables

GROUP AVERAGE

EFFECTS

P-VALUE

STD. DEV

P-VALUE

MAIN EFFECTS

\begin{tabular}{|c|c|c|c|c|}
\hline Coffee & 0.012 & 0.974 & 2.412 & $0.000^{k \cdots *}$ \\
\hline Calories & -0.732 & $0.000^{* * *}$ & 0.558 & 0.191 \\
\hline Origin & -0.583 & $0.004^{* *}$ & 0.258 & 0.693 \\
\hline Price & -0.302 & $0.000^{* * *}$ & 0.116 & 0.255 \\
\hline \multicolumn{5}{|c|}{ INTERACTIONS AMONG CONJOINT VARIABLES } \\
\hline Coffee*Calories & -0.009 & 0.951 & 0.519 & 0.193 \\
\hline Coffee*Origin & 0.261 & 0.236 & 0.629 & 0.171 \\
\hline Coffee*Price & 0.058 & $0.027^{*}$ & 0.021 & 0.480 \\
\hline Calories*Origin & 0.101 & 0.551 & 0.026 & 0.935 \\
\hline Calories*Price & -0.005 & $0 . .833$ & 0.080 & $0.019^{*}$ \\
\hline Origin*Price & -0.020 & 0.467 & 0.057 & 0.314 \\
\hline \multicolumn{5}{|c|}{ INTERACTIONS WITH SOCIODEMOGRAPHIC VARIABLES } \\
\hline Coffee*Gender & 0.722 & 0.068 & 1.436 & $0.010^{*}$ \\
\hline Coffee*Age & -0.727 & 0.070 & 1.183 & $0.001^{* * *}$ \\
\hline Calories*Gender & 0.569 & $0.013^{*}$ & 0.061 & 0.858 \\
\hline Calories*Age & -0.181 & 0.334 & 0.635 & $0.001^{* * *}$ \\
\hline Origin*Gender & 0.059 & 0.714 & 0.605 & 0.263 \\
\hline Origin*Age & 0.205 & 0.255 & 1.131 & $0.007^{* *}$ \\
\hline Price*Gender & -0.011 & 0.738 & 0.052 & 0.647 \\
\hline Price*Age & 0.049 & 0.222 & 0.137 & 0.479 \\
\hline
\end{tabular}

${ }^{* * *}$ and ${ }^{* * * *}$ indicate significant effects at $0.05,0.01$ and 0.001 levels, respectively. 
Appendix A - Rating design

\begin{tabular}{|c|c|c|c|c|}
\hline PRODUCT & TYPE OF COFFEE & $\begin{array}{l}\text { CALORIES } \\
(\mathrm{kcal} / 100 \mathrm{ml})\end{array}$ & COUNTRY OF ORIGIN & PRICE (NOK) \\
\hline 1 & Espresso & 90 & Italy & Kr. 29,- \\
\hline 2 & Latte & 90 & Norway & Kr. 23,- \\
\hline 3 & Latte & 60 & Norway & Kr. 23,- \\
\hline 4 & Espresso & 60 & Norway & Kr. 17,- \\
\hline 5 & Latte & 90 & Norway & Kr. 29,- \\
\hline 6 & Espresso & 60 & Norway & Kr. 29,- \\
\hline 7 & Espresso & 90 & Norway & Kr. 17,- \\
\hline 8 & Latte & 90 & Italy & Kr. 17,- \\
\hline 9 & Latte & 60 & Italy & Kr. 29,- \\
\hline 10 & Espresso & 90 & Italy & Kr. 23,- \\
\hline 11 & Latte & 60 & Italy & Kr. 17,- \\
\hline 12 & Espresso & 60 & Italy & Kr. 23,- \\
\hline
\end{tabular}




\section{Appendix B - Choice design}

\begin{tabular}{|c|c|c|c|c|c|}
\hline SET & $\begin{array}{l}\text { CORRESPONDING } \\
\text { PRODUCT ID IN } \\
\text { RATING DESIGN } \\
\text { (Table 3) }\end{array}$ & COFFE TYPE & $\begin{array}{c}\text { CALORIES } \\
\text { (kcal per } 100 \mathrm{ml} \text { ) }\end{array}$ & ORIGIN & $\begin{array}{l}\text { PRICE } \\
\text { (NOK) }\end{array}$ \\
\hline \multirow{3}{*}{1} & 10 & Espresso & 90 & Italy & 23 \\
\hline & & Latte & 60 & Norway & 17 \\
\hline & 5 & Latte & 90 & Norway & 29 \\
\hline \multirow{3}{*}{2} & & Latte & 90 & Italy & 29 \\
\hline & 8 & Latte & 90 & Italy & 17 \\
\hline & & Espresso & 60 & Norway & 23 \\
\hline \multirow{3}{*}{3} & 6 & Espresso & 60 & Norway & 29 \\
\hline & 11 & Latte & 60 & Italy & 17 \\
\hline & 2 & Latte & 90 & Norway & 23 \\
\hline \multirow{3}{*}{4} & & Espresso & 90 & Norway & 29 \\
\hline & 12 & Espresso & 60 & Italy & 23 \\
\hline & 11 & Latte & 60 & Italy & 17 \\
\hline \multirow{3}{*}{5} & 4 & Espresso & 60 & Norway & 17 \\
\hline & 9 & Latte & 60 & Italy & 29 \\
\hline & & Latte & 90 & Italy & 23 \\
\hline \multirow{3}{*}{6} & & Latte & 60 & Norway & 29 \\
\hline & 7 & Espresso & 90 & Norway & 17 \\
\hline & 12 & Espresso & 60 & Italy & 23 \\
\hline \multirow{3}{*}{7} & 2 & Latte & 90 & Norway & 23 \\
\hline & & Espresso & 90 & Italy & 17 \\
\hline & & Espresso & 60 & Italy & 29 \\
\hline \multirow{3}{*}{8} & 3 & Latte & 60 & Norway & 23 \\
\hline & 1 & Espresso & 90 & Italy & 29 \\
\hline & 7 & Espresso & 90 & Norway & 17 \\
\hline
\end{tabular}




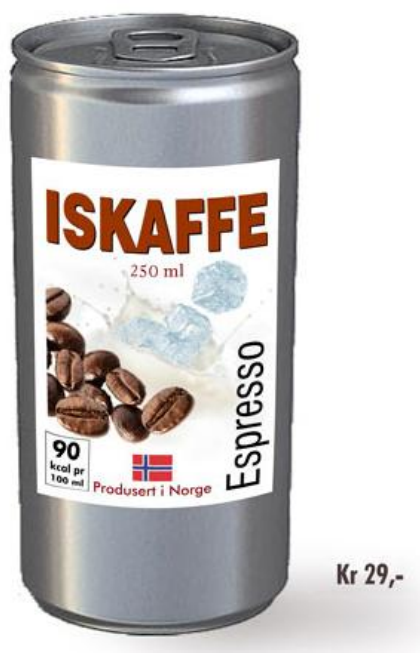

Figure 1 - One of the iced coffee profiles 


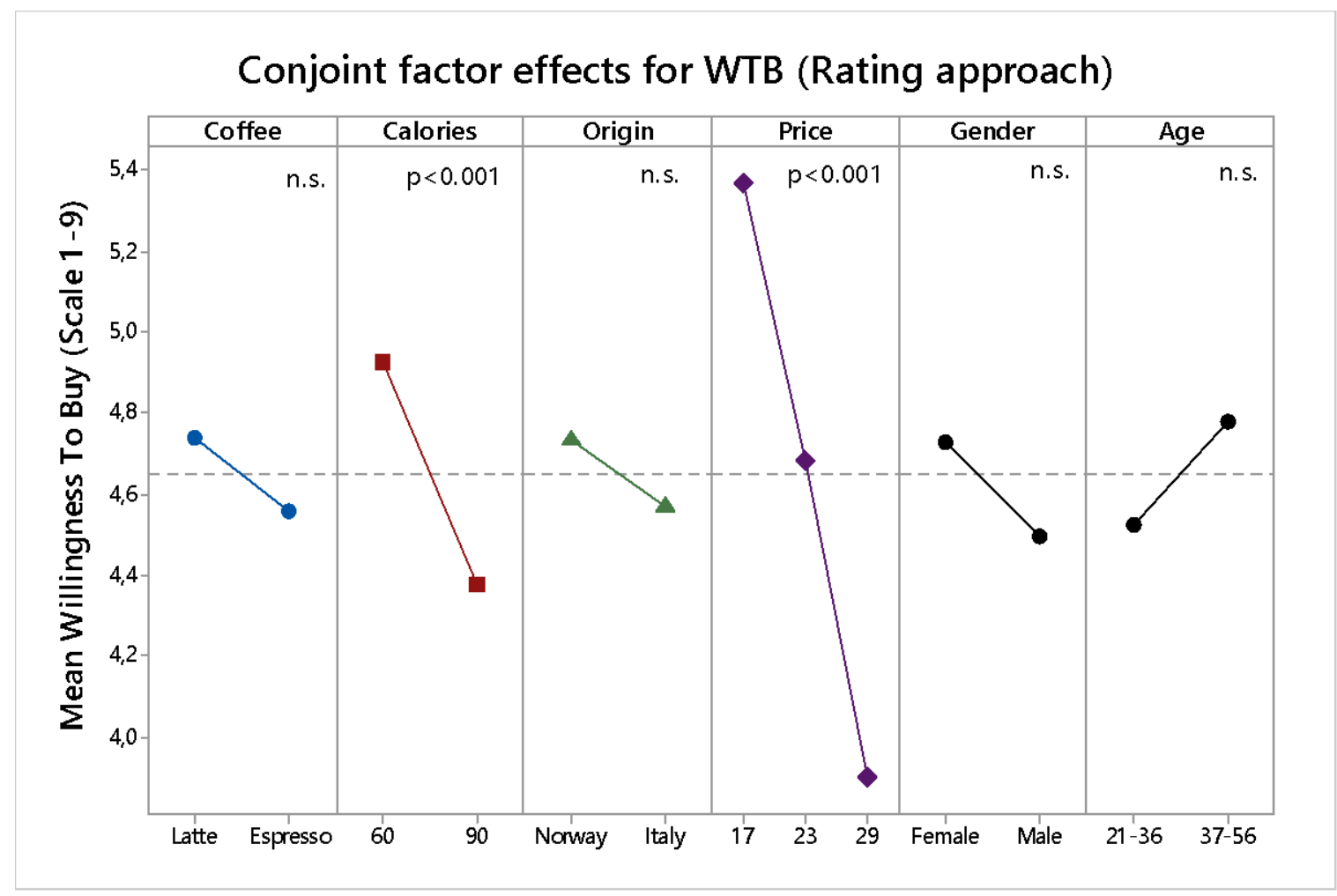

Figure 2 - Main effects in the Mixed Model ANOVA from conjoint rating (n.s.: nonsignificant effects) 


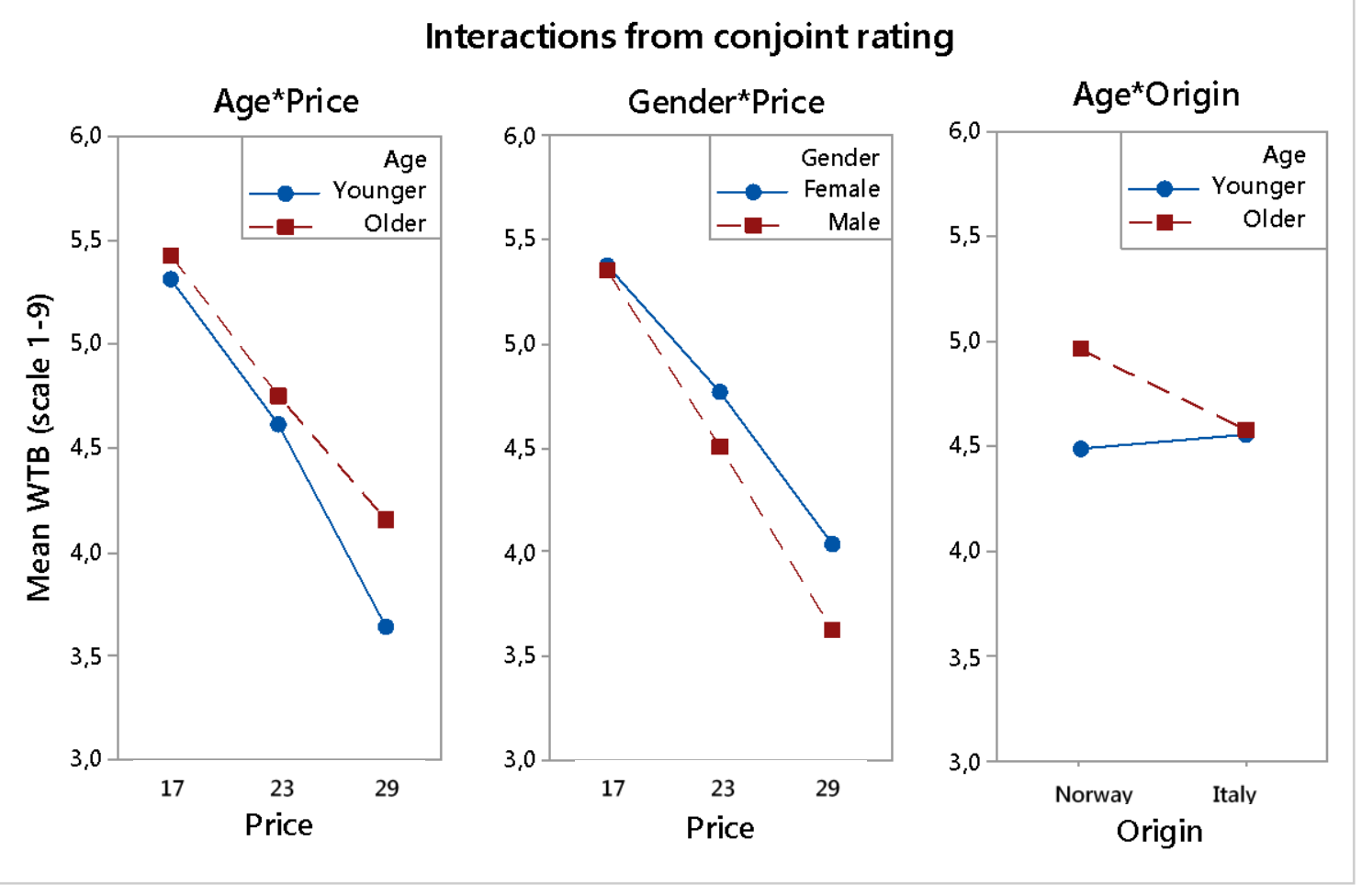

Figure 3 - Significant interaction effects from the rating approach 


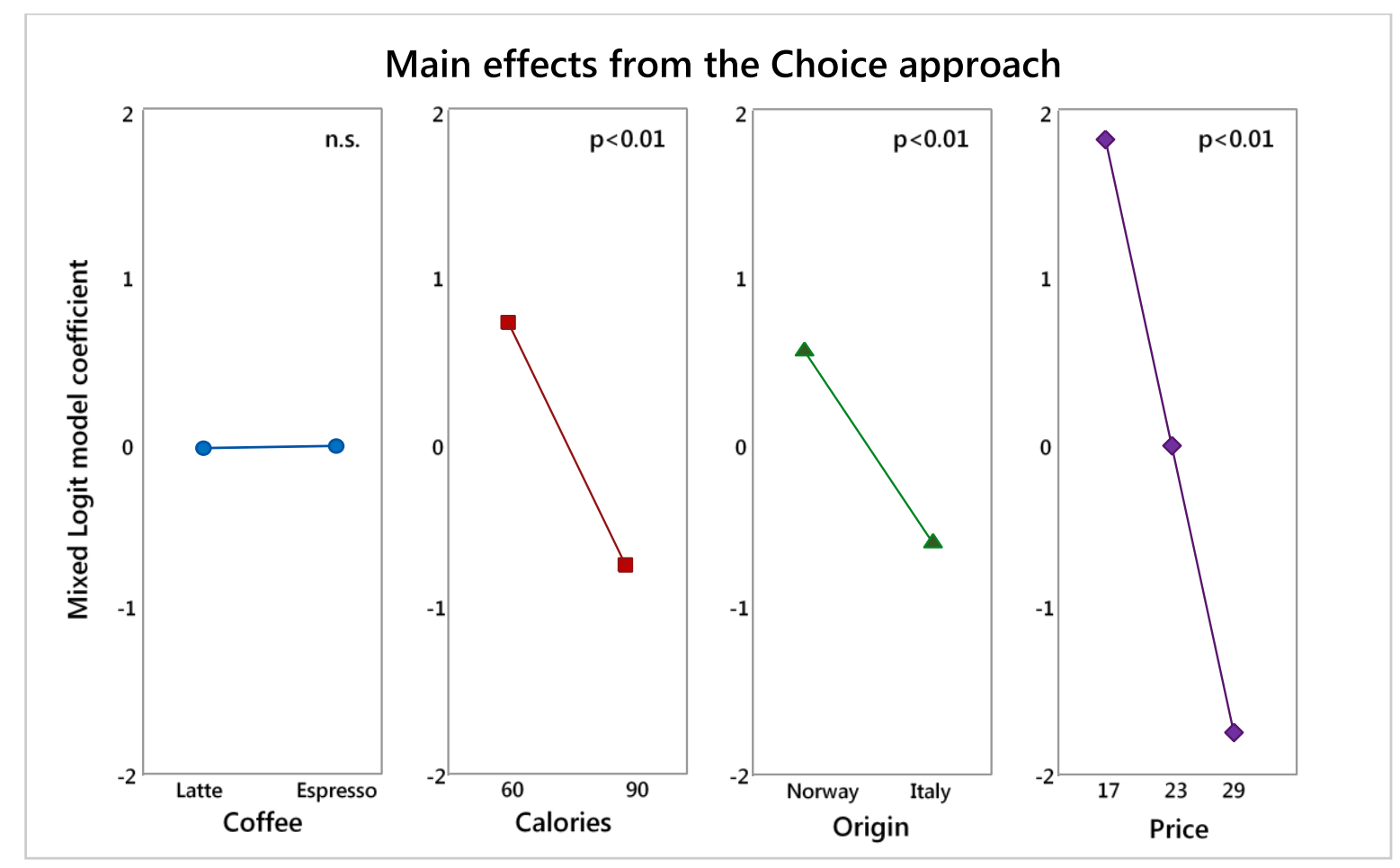

Figure 4 - Main effects in the ML Model from choice-based conjoint (n.s.: non-significant effect). 

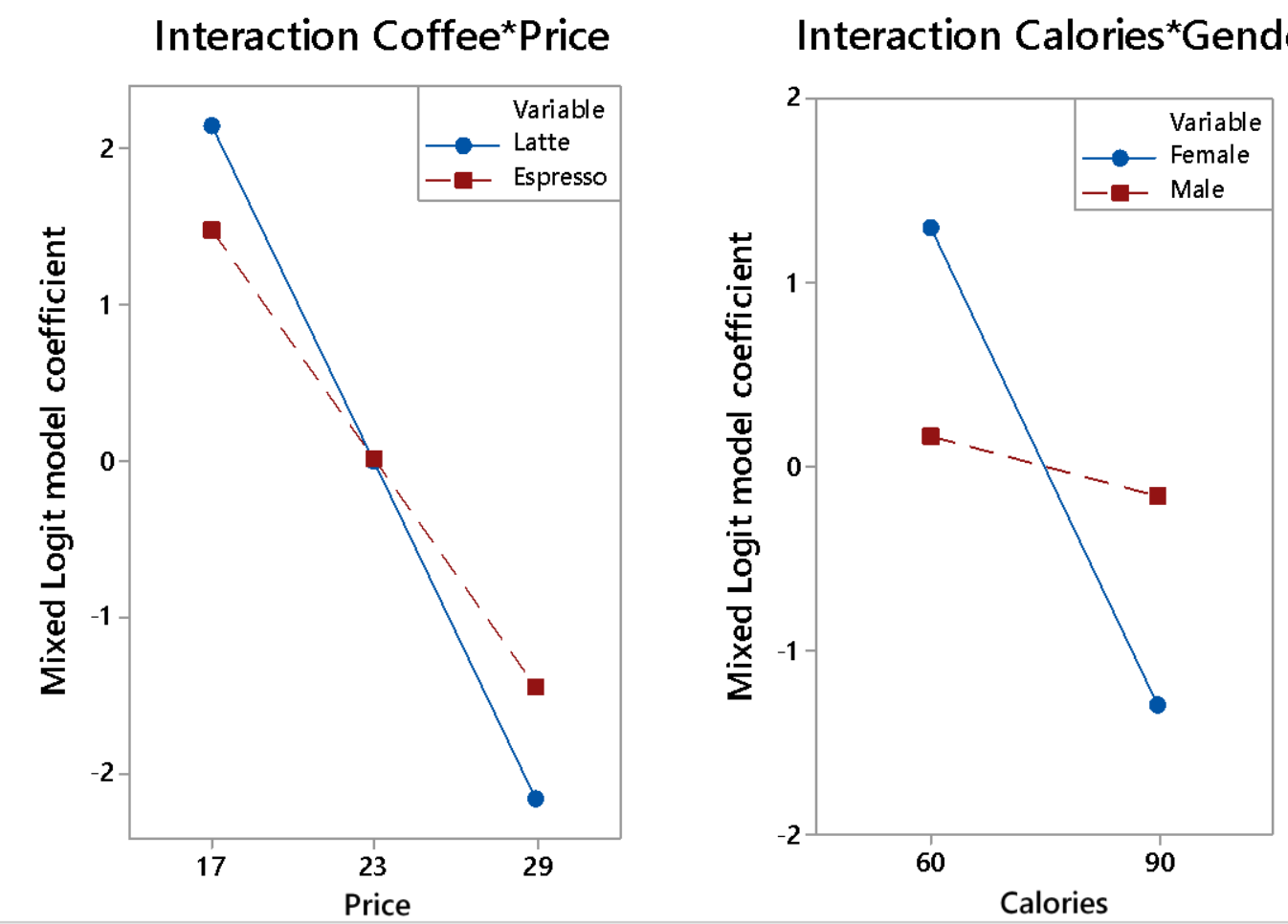

Figure 5 - Significant interaction effects from the choice-based approach 


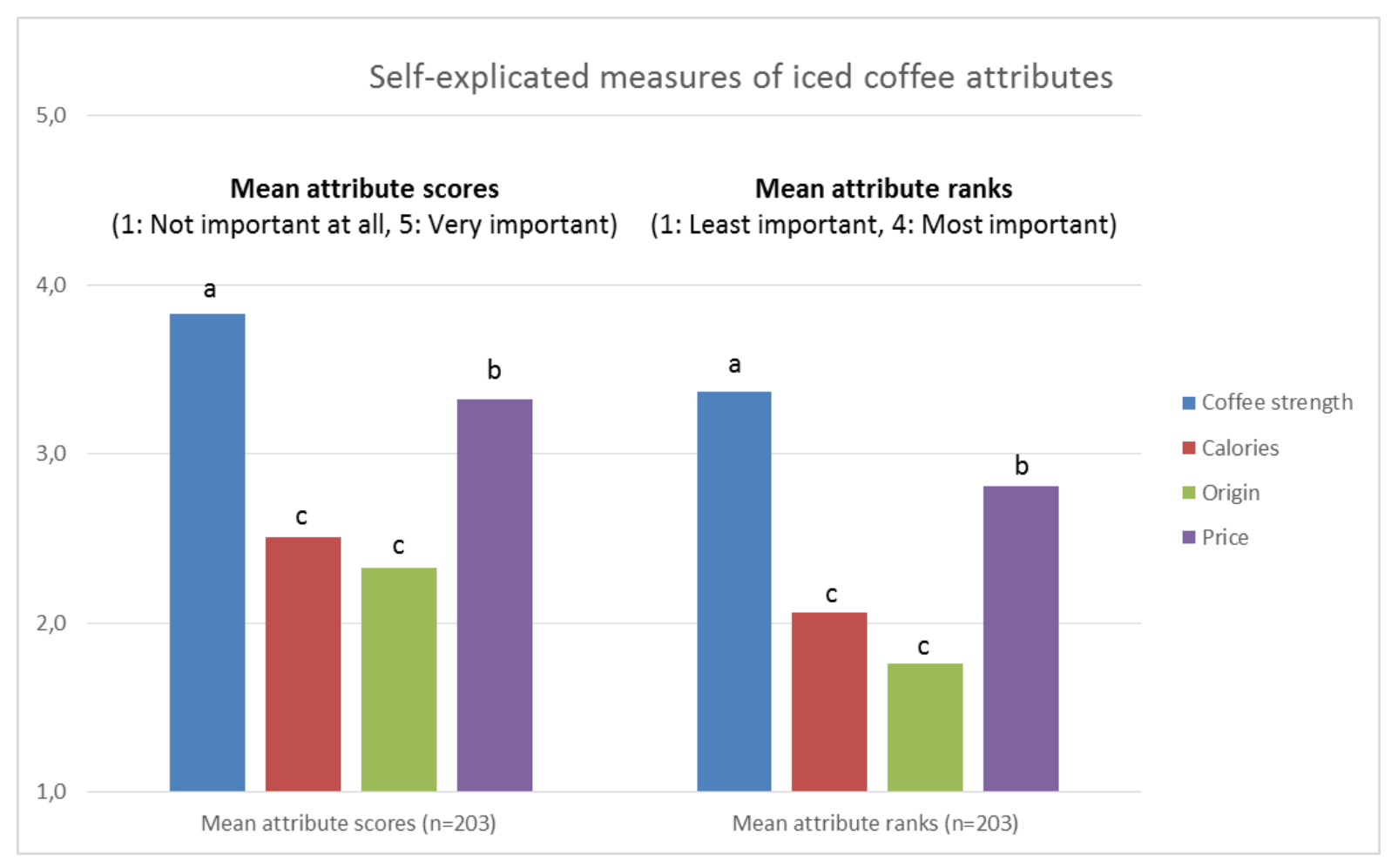

Figure 6 - Importance of iced coffee attributes by direct rating and ranking of attributes in self-explicated tests, pulled data for all consumers. Similar letters indicate non-significant differences. 


\section{Highlights:}

- Two approaches are compared: Rating-based and Choice-based conjoint experiments.

- We tested the approaches on different product profiles of iced coffees with Norwegian consumers.

- Product profiles varied in coffee type, production origin, calorie content and price.

- Rating data were analysed by Mixed Model ANOVA while choice data were analysed by Mixed Logit Model.

- Approaches are compared in terms of data analysis, outcomes, estimation power and practicalities. 